Güzel, A. ve Karadağ, Ö. (2013). Anlatma becerileri açısından “Türkçe Dersi Öğretim Programı (6, 7, 8. Sınıflar)"na eleştirel bir bakış. Ana Dili Eğitimi Dergisi, 1(1), 45-52.

Ana Dili Eğitimi Dergisi
Journal of Mother Tongue Education
ADED - JOMTE
www.anadiliegitimi.com

\title{
Anlatma Becerileri Açısından “Türkçe Dersi Öğretim Programı (6, 7, 8. Sınıflar)”na Eleştirel Bir Bakış ${ }^{*}$ \\ Abdurrahman Güzel* \\ Özay Karadağ ${ }^{* * *}$
}

Özet

Eğitim sürecinin en önemli unsurlarından biri, kuşkusuz öğretim programlarıdır. Yaşamın başarılı bir biçimde sürdürülmesini sağlayacak becerilerin öğrencilere kazandırılmasında, öğretim programları kılavuzluk etmelidir. Bir öğretim programı, hedeflediği alanda, kişinin kısa ve uzun vadede sahip olması gereken becerileri öngörebilmeli, bu becerilerin kişilere kazandırılmasının geçerli yollarını öğretmenlere sunabilmelidir. Bu açıdan, öğretim programlarının, zaman içinde oluşan intiyaçlara ya da bilimsel alandaki yeni gelişmelere göre, güncellenmesi ya da tümden değiştirilmesi söz konusu olabilir. Türkiye'de, benzer gerekçelerle, 2004 yılından itibaren yeni öğretim programları hazırlanmış ve yürürlüğe girmiştir. 2006 yılında yürürlüğe giren ilköğretim Türkçe Dersi Öğretim Programı ve Kılavuzu (6, 7, 8. Sınıflar)'nda Türkçe dersi dinleme, konuşma, okuma, yazma ve dilbilgisi öğrenme alanlarından oluşmuştur. Öğrenme alanları için amaçlar ve bu amaçlar altında kazanımlar belirlenmiştir. Bu çalışmada, ilköğretim Türkçe Dersi Öğretim Programı ve Kılavuzu $(6,7$, 8. Sınıflar) anlatma becerileri olan konuşma ve yazma açısından incelenmiştir. Programda konuşma ve yazma öğrenme alanları için oluşturulan kazanımlar ele alınarak değerlendirilmiştir. Çalışmada, kazanımların bir kısmının konuşma ve yazma öğrenme alanının özelliklerini tam olarak yansıtmadığı, kazanımlarda ifade yanlışlıkları olduğu, bazı kazanımların çok genel bazılarınınsa çok ayrıntılı olduğu ve bazı kazanımların da işe vuruk olmadığı belirlenmiştir.

Anahtar Kelimeler: Türkçe Eğitimi, Türkçe Öğretim Programı, Konuşma, Yazma, Kazanım.

\section{A Critical Look at Turkish Curriculum (6, 7 and $8^{\text {th }}$ Grades) in Accordance with Explanation Abilities}

\begin{abstract}
Curriculums are certainly the one of the most essential elements of education process. Curriculum should guide students in acquiring abilities which can help them to maintain their lives successfully. A curriculum should predict the abilities which an individual must have at a short and also long term, and should present teacher the ways of acquiring these abilities. From this point of view, updating or making innovations at these curriculums according to the needs occurred in time or new developments in science can be mentioned. . In Turkey, new curriculums have been prepared and become valid since 2004. The Elementary Turkish Educational Curriculum and Guidebook (6, 7 and $8^{\text {th }}$ grades); that has become valid in 2006, consists of learning domains such as speaking, reading, writing and grammar. Aims have been fixed for each learning domain and acquirements have been formed under aims title. In this study, Elementary Turkish Curriculum and Its Guidebook $\left(6,7\right.$ and $8^{\text {th }}$ Grades) is examined according to speaking and writing abilities that are among explanation abilities. Acquirements formed for speaking and writing are evaluated in the curriculum. In the study, it is determined that some parts of acquirements don't reflect the qualities of learning domains of speaking and writing enough,
\end{abstract}

\footnotetext{
* Bu çalışma, 5. Uluslararası Dünya Dili Türkçe Sempozyumu’nda sözlü bildiri olarak sunulmuştur.

*** Prof. Dr., Başkent Üniversitesi, Eğitim Fakültesi, Türkçe Eğitimi Bölümü. Ankara.

E-posta:guzel@baskent.edu.tr

*** Yrd.Doç.Dr. Düzce Üniversitesi, Eğitim Fakültesi, Türkçe Eğitimi Bölümü. Düzce.

E-posta: ozaykaradag@gmail.com
} 
there are also some expressional mistakes in acquirements and some acquirements are very general, some of them are very detailed and some also cannot be measured and evaluated quite well.

Key Words: Turkish Education, Turkish Curriculum, Speaking, Writing, Acquirements.

\section{Giriş}

Okulda verilen eğitim sistematik olarak gerçekleşir ve bu sistemin önemli ayaklarından biri de öğretim programlardır. "Bir dersle ilgili öğretme-öğrenme sürecinde nelerin, niçin ve nasıl yer alacağını gösteren bir kılavuz, başka bir deyişle bu nitelikte bir proje planı" (Özçelik, 1992: 4) olarak tanımlanan öğretim programı, okullardaki eğitim-öğretim etkinliklerinin belirleyicisidir.

Öğretim programı, yaşamda ihtiyaç duyulabilecek bilgi ve becerileri öngörerek, bunları belirli sürelerde öğrencilere kazandırmayı hedefler. Program içeriğinin isabetli olarak belirlenmesi, öngörünün güçlü olmasına bağııdır. Güçlü bir öngörüye rağmen, zaman içinde ortaya çıkan gelişmeler, gündelik yaşamın farklılaşan ihtiyaçları programlarda değişikliğe gidilmesi gerektirebilir.

Bir programın uygulanması sırasında yapılan gözlemler, program çıktılarının eksik ya da olumsuz olduğunu ortaya koyabilir. Erden (1998: 22), eğitim programlarının genel ve özel hedeflerinin yanlış belirlenmiş olabileceğini ya da öğretim faaliyetlerinde öğrenci-öğretmen, öğrenciöğrenci etkileşimi sonucu programın beklendik ürünlerinin yanı sıra, beklenmedik ürünlerinin de ortaya çıkabileceğini bildirmektedir.

Program içeriğinin çağın gereklerini yerine getirebilmede yetersiz kalması ve/veya uygulamaya ilişkin yapılan gözlemlerde elde edilen olumsuz sonuçlar, öğretim programlarının güncellenmesini ya da tümden değiştirilmesini zorunlu kılabilir. Bu olağan bir durumdur ve Varış'ın belirttiği gibi (1976: 25), "toplumsal dinamizm eğitim programlarının da dinamik olmasını gerektirmektedir."

Türkiye'de de benzer gerekçelerle 2004 yılından itibaren program yenileme çalışmaları başlamış, 2005 yılında ilköğretim birinci kademede Türkçe dersi için "ilköğretim Türkçe Dersi Öğretim Programı ve Kılavuzu (1-5. Sınıflar)", 2006 yılında ilköğretim ikinci kademede Türkçe dersi için “ilköğretim Türkçe Dersi Öğretim Programı ve Kılavuzu (6, 7, 8. Sınıflar)" yürürlüğe girmiştir.

Türkçe Dersi Öğretim Programı (6, 7, 8. Sınıflar)'nda (MEB, 2006: 5) Türkçeyi doğru, güzel ve etkili kullanma, eleştirel düşünme, yaratıcı düşünme, iletişim kurma, problem çözme, araştırma, karar verme, bilgi teknolojilerini kullanma ve girişimcilik temel beceriler olarak sıralanmıştır. Öğrencilerin, bu becerileri yatay olarak bir yılın sonunda dikey olarak sekizinci sınıfın sonunda kazanmaları ve hayat boyu kullanmaları hedeflenmiştir.

Illköğretim seviyesinde öğrencilerin dille ilgili edinecekleri bilgi, beceri, tutum ve değerler son derece önemlidir. Öğrencilerin ilköğretim okullarında kazanacakları bu özellikler, onların hem eğitim hayatını hem de okul dışı yaşamlarını güvenli, başarılı, sorunsuz ve mutlu bir biçimde sürdürmelerini sağlayacaktır. Burada, dili ne kadar ve nasıl öğreteceğiz sorusu karşımıza çıkmaktadır. Yalçın (2002: 33-35) bu soruya açıklık getirmek üzere dil eğitiminin en genel amaçlarını; "algılamaya yönelik (Cognitive) olmak, iletişime yönelik (Communicative) olmak, işlevsel (Functional) olmak, plânlama becerisine yönelik olmak" biçiminde dört ana grupta toplamıştır. Yalçın (2002: 33-35) bu gruplamanın dil öğretiminde üzerinde uzlaşılmış amaçlar olduğunu belirterek, bu amaçları gerçekleştirebilecek düzeyde bir dil öğretiminin gerekliliğini ifade etmiştir

Öğrencilerin Türkçe dersi ile hedeflenen becerileri elde etmesi, Türkçe Dersi Öğretim Programı'ndaki kazanımların gerçekleşmesi ile mümkün olabilir. Kazanımlar, "öğretim süreci içerisinde planlanmış yaşantılarla öğrencide görülmesi beklenen bilgi, beceri, tutum ve değerlerdir"(MEB, 2006: 11). Programda, kazanımlar öğrenme alanları altında yer almıştır. Anlama becerileri olan dinleme ve okuma, anlatma becerileri olan konuşma ve yazma ile dilbilgisi öğrenme alanlarını oluşturmaktadır. 
Illköğretim Türkçe Dersi Öğretim Programı (6, 7, 8. Sınıflar) (MEB, 2006) kazanımlar yoluyla öğrencilerin bilgi ve beceri edinmesini, tutumlar geliştirmesini ve değerler kazanmasını hedeflemektedir. Türkçe eğitimiyle bu düzeye ulaşılabilmesi için programın hedefleri olan kazanımların nitelikleri üzerinde dikkatle durulmalıdır. Programla hedeflenen düzey, kuşkusuz bireyin yaşamını güvenli, başarılı ve mutlu bir biçimde sürdürmesini sağlayacaktır. Ancak bu özelliklerin sonuç olarak elde edilebilmesi için öncelikle programın eksiksiz, uygulamada tereddüde yer bırakmayacak şekilde açık ve net olması gerekmektedir.

İlköğretim Türkçe Dersi Öğretim Programı (6,7,8. Sınıflar) Baş tarafından (2012) yazılı ve sözlü kültür bağlamında ele alınmış ve bu çalışmada kazanımlara ilişkin önemli eleştiriler getirilmiştir. Benzer bir çalışma Karadağ (2012) tarafından anlama becerileri olan dinleme ve okuma kazanımları için gerçekleştirilmiş ve çalışmada, kazanımların belirlenmesinde eksikliklerin olduğu, genelleme ve tekrarların bulunduğu, bazı kazanımların işe vuruk olmadığı belirlenmiştir.

Eğitimde hedeflerin, Türkçe Dersi Öğretim Programı(6, 7, 8. Sınıflar)'ndaki (MEB, 2006) biçimiyle kazanımların, toplumun hedef ve ihtiyaçlarına, öğrencilerin ihtiyaçlarına, konu alanının özelliklerine uygun, birbirleriyle tutarlı, açık biçimde ifade edilmiş ve gerçekleşebilecek nitelikte olmaları gerekmektedir. Bu özellikler hedeflerin değerlendirilmesinde temel alınacak kıstaslardır (Erden, 1998: 24).

Bu araştırmanın amacı, 2006 yılında yürürlüğe giren “ilköğretim Türkçe Dersi Öğretim Programı ve Kılavuzu(6, 7, 8. Sınıflar)'nda (MEB, 2006) anlatma becerileri olarak yer alan konuşma ve yazma öğrenme alanlarının kazanımlarını anlatma becerilerinin özellikleri açısından değerlendirmektir.

\section{Yöntem}

Öğretim programının incelenmesine amacıyla yapılan bu araştırma bir durum çalışmasıdır. Çalışmanın verileri nitel araştırma tekniklerinden doküman incelemesi yoluyla elde edilmiştir. Doküman incelemesi, "araştırılması hedeflenen olgu veya olgular hakkında bilgi içeren yazılı materyallerin analizini kapsar" (Yıldırım ve Şimşek, 2005: 187).

Çalışmada temel doküman olarak Illköğretim Türkçe Dersi Öğretim Programı ve Kılavuzu(6, 7, 8. Sınıflar)(MEB, 2006) ele alınmış, programda öğrenme alanı olarak yer alan konuşma ve yazma becerilerinin amaç ve kazanımları incelenmiştir.

Anlatma becerileri olan ve programda öğrenme alanı olarak yer alan konuşma ve yazma amaç ve kazanımlarına ilişkin bulgular değerlendirilerek doğrudan raporlaştırma yoluna gidilmiştir.

\section{Bulgular Ve Yorum}

İlköğretim Türkçe Dersi Öğretim Programı ve Kılavuzu(6, 7, 8. Sınıflar)'unda (MEB, 2006: 5), temel dil becerileri öğrenme alanları olarak kabul edilmiş ve kazanımlar dört temel dil becerisi olan, dinleme, konuşma, okuma, yazma ve bu becerileri destekleyen kurallar bütünü olarak dil bilgisi başlıkları altında oluşturulmuştur. Bu çalışmada anlatma becerileri olan konuşma ve yazma öğrenme alanlarının amaç ve kazanımlarına yönelik değerlendirmelere yer verilmiştir.

\section{Konuşma Öğrenme Alanı}

Türkçe Dersi Öğretim Programı (6, 7, 8. Sınıflar) (MEB, 2006) konuşma öğrenme alanında beş amaç altında 42 kazanım yer almaktadır. Konuşma öğrenme alanının amaçları şunlardır:

1. Konuşma kurallarını uygulama

2. Sesini ve beden dilini etkili kullanma

3. Hazırlıklı konuşmalar yapma 
4. Kendini sözlü olarak ifade etme alışkanlığı kazanma

5. Kendi konuşmasını değerlendirme

Konuşma öğrenme alanına ilişkin elde edilen bulgular ve yorumlar amaçların sıralamasına uygun olarak maddeler hâlinde aşağıda verilmiştir.

1. Konuşma kurallarını uygulama amacı altında 13 kazanım yer almaktadır. Bu amaç altında yer alan "4. Standart Türkçe ile konuşur."(MEB, 2006: 19) kazanımı "5. Türkçenin kurallarına uygun cümleler kurar."(MEB, 2006: 19) kazanımını doğal olarak içermektedir.

Bir dilin standart biçimi yazı dili olarak kullanılan ölçünlü dil olduğundan cümle teşkilleri dil kurallarına uygun olmak durumundadır. Bu açıdan bakıldığında standart Türkçe ile konuşmak Türkçenin kurallarına uygun cümleler kurmak anlamına gelmektedir. Iki kazanım, genellik özellik açısından bir arada değerlendirildiğinde "4. Standart Türkçe ile konuşur."(MEB, 2006: 19) kazanımı genel ve kapsayıcı, "5. Türkçenin kurallarına uygun cümleler kurar."(MEB, 2006: 19) kazanımı bu kazanıma göre daha özel ve kapsanan durumundadır. Bu sebeple "4. Standart Türkçe ile konuşur."(MEB, 2006: 19) kazanımına "Türkçenin kurallarına uygun cümleler kurar." açıklaması eklenebilir.

2. Konuşma kurallarını uygulama amacında bulunan "3. Bulunduğu ortama uygun bir konuşma tutumu geliştirir." (MEB, 2006: 19) kazanımı yanlıştır.

Tutum duyuşsal bir özelliktir. Beğenmek, hoşlanmak, memnun olmak gibi olumlu tutumlar söz konusu olabileceği gibi beğenmemek, hoşlanmamak, nefret etmek gibi olumsuz tutumlar da söz konusu olabilir. Eğitim yoluyla öğrencilerin genel olarak konuşma becerisine ilişkin olumlu tutumlar kazanması beklenir. Örneğin, bir grup karşısında kendini ifade etmekten hoşlanmak, bu olumlu tutumlardan biri olabilir. Bu kazanımla ifade edilmek istenen, öğrencinin bulunduğu ortama uygun bir konuşma tutumu geliştirmesi değil, bulunduğu ortama uygun bir konuşma tavrı/üslubu geliştirmesidir. Kazanım "Bulunduğu ortama uygun bir konuşma tavrı/üslubu geliştirir." biçiminde değiştirilmelidir.

3. Konuşma kurallarını uygulama amacında "13. Konuşmayı uygun ifadelerle bitirir." (MEB, 2006: 19) kazanımı yer almaktadır ve bir konuşma kuralı olarak bu amaç altında yer alması isabetlidir. Kazanımın açıklaması "Teşekkür ederim, görüşmek üzere vb. ifadeler üzerinde durulur." şeklinde yapılmıştır. Bu kazanımın içeriği hazırıklı konuşmalar yapma (MEB, 2006: 21) amacında yer alan "11. Konuşmasını belirlenen sürede ve teşekkür cümleleriyle bitirir." kazanımı ile büyük oranda örtüşmektedir. Mevcut durum kazanım tekrarı olarak değerlendirilebilir.

4. Sesini ve beden dilini etkili kullanma amacında kazanım eksikliği bulunmaktadır. Sesin anlam ayırt edici özelliklerini kullanabilmeyi öğrencilere kazandırmaya yönelik olarak sadece "8. Canlandırmalarda, sesini varlık ve kahramanları çağrıştıracak şekilde kullanır." (MEB, 2006: 20) kazanımı yer almaktadır. Sesteki duygu tonlarını doğru olarak aktarmaya yönelik kazanımların bu amaç altında yer alması gerekmektedir. Ayrıca bu amaç altında yer alan kazanımlar sesle ilgili olanlar ve beden dili ile ilgili olanlar şeklinde gruplanmalıdır.

5. Hazırlıklı konuşmalar yapma amacında bulunan, "8. Konuşma öncesinde konuyla ilgili açıklamalar yapar." (MEB, 2006) kazanımı yanlış ifade edilmiştir.

Kazanımda yer alan öncesinde kelimesi yanlış yoruma sebep olabilir. Kazanım mevcut şekliyle değerlendirildiğinde, konuşmacının kürsüye geçmeden önce karşılaştığı kişilere konuşma hakkında bilgiler vereceği sonucu da çıkarılabilir. Kazanımın açıklaması, "Konunun geçmişi, konuşma sırasında nelere değinileceği dinleyicilere açıklanır.", şeklinde yapılmıştır. Bu sebeple kazanım, "Konuşmasının başında konuyla ilgili açıklamalar yapar." şeklinde düzeltilmelidir.

6. Kendi konuşmasını değerlendirme amacında "1. Konuşmasının içerik yönünden değerlendirir." (MEB, 2006: 22) kazanımı yer almaktadır. Konuşma içeriğinin düzenlenmesine ilişkin kazanımlar farklı amaçlar altında yer almıştır. Bu sebeple öğrenme alanına konuşma içeriğinin 
düzenlemesine ilişkin müstakil bir amaç eklenebilir ve ilgili kazanımlar bu amaç altında bir araya getirilebilir.

7. Kendi konuşmasını değerlendirme amacı altında yer alan kazanımlar kolayca ölçülüp değerlendirilebilir olmaktan uzaktır. Bu amaç altında yer alan kazanımlar (MEB, 2006: 22) şunlardır:

"1. Konuşmasını içerik yönünden değerlendirir.

2. Konuşmasını dil ve anlatım yönünden değerlendirir.

3. Konuşmasını sunum tekniği yönünden değerlendirir.

4. Konuşmasını, sesini ve beden dilini kullanma yönünden değerlendirir."

Kazanımların açıklama bölümünde hangi içerik unsurlarının, dil, anlatım ve sunum tekniği özelliklerinin ele alınacağına ilişkin bilgi verilmemiş, sadece hangi ölçme/değerlendirme araçlarının kullanılabileceğine ilişkin bilgi verilmiştir. Kazanımların gerçekleştirilmesinde kullanılabilecek etkinlik örnekleri bölümü boş bırakılmıştır. Bu bölümün boş bırakılmasının sebebi kazanımların çok genel olmasıdır.

"4. Konuşmasının sesini ve beden dilini kullanma yönünden değerlendirir."(MEB, 2006: 22) kazanımı ayrıca ele alınmalıdır. Ses ve beden dili kuşkusuz birbiriyle ilişkili kavramlardır. Ancak ses işitme duyusuna, beden dili ise görme duyusuna etki etmektedir. İki farklı duyuya etki eden özellikler bu kazanımda bir araya gelmektedir. Bu bakımdan kazanımda yer alan özelliklerin bir etkinlik içinde değerlendirilme olasılığı azalmaktadır. Ayrıca sesini ve beden dilini etkili kullanma amacı dokuz kazanımla verilmişken bunun değerlendirilmesinin bir kazınama yüklenmiş olması kabul edilemez.

8. Kendini sözlü olarak ifade etme alışkanlığı kazanma amacında yer alan kazanımlar yeterli değildir. Bu amaç altında farklı konuşma durumlarına işaret edecek kazanımların yer alması gerekmektedir. Örneğin "Sınıf ve okul temsilleri, kutlama törenleri vb. etkinliklerde görev alır.", biçiminde bir kazanımın bu amaç altında yer alması konuşma becerisi açısından son derece isabetli olur.

9. Programda söz varlığının kullanılmasına yönelik müstakil bir amaç bulunmamaktadır. Söz varlığına ilişkin kazanımlar farklı amaçlar altında yer almıştır. Konuşma kurallarını uygulama amacı altında "6. Yabancı dillerden alınmış, dilimize henüz yerleşmemiş kelimelerin yerine Türkçelerini kullanır.", (MEB, 2006: 19), hazırlıklı konuşmalar yapma amacı altında "6. Atasözü, deyim ve söz sanatlarını uygun durumlarda kullanarak anlatımını zenginleştirir." (MEB, 2006: 21) ve kendini sözlü olarak ifade etme alışkanlığı kazanma (MEB, 2006: 23) amacı altında "4. Yeni öğrendiği kelime, kavram, atasözü ve deyimleri kullanır." kazanımı yer almaktadır.

10. Program bir topluluk karşısında hazırlıklı konuşma yapmayı amaç olarak belirlemiş ve buna ilişkin özellikleri bu amaç altında kazanımlaştırmıştır. Insanların yaşamlarında bir topluluk karşısında hazırlıksız konuşma yapma ihtimalleri de oldukça yüksektir ve bu sebeple topluluk karşısında hazırlıksız konuşma yapmaya ilişkin özelliklerin de kazanımlaştırılması gerekmektedir.

Kişilerarası iletişimde konuşma becerisin daha etkili kullanılmasına yönelik özelliklerin programda kazanım olarak yer almadığı görülmektedir. Kişilerarasında iletişimi başlatma ve sürdürme açısından konuşma becerisinin geliştirilmesi öğrencilerin gündelik hayatlarını daha başarılı olarak sürdürmelerine yardımcı olacaktır. Kişilerarası iletişimi geliştirmeye yönelik konuşma kazanımlarının programa dâhil edilmesi isabetli olacaktır.

\section{Yazma Öğrenme Alanı}

Türkçe Dersi Öğretim Programı $(6,7,8$. Sınıflar) (MEB, 2006) yazma öğrenme alanında altı amaç altında 42 kazanım yer almaktadır. Yazma öğrenme alanının amaçları şunlardır:

1. Yazma kurallarını uygulama

2. Planlı yazma 
3. Farklı türlerde metinler yazma

4. Kendi yazdıklarını değerlendirme

5. Kendini yazılı olarak ifade etme alışkanlığı kazanma

6. Yazım ve noktalama kurallarını uygulama

Yazma öğrenme alanına ilişkin elde edilen bulgular ve yorumlar amaçların sıralamasına uygun olarak maddeler hâlinde aşağıda verilmiştir.

1. Yazma kurallarını uygulama amacı altında 11 kazanım yer almaktadır. Bu amaç altında yer alan "4. Standart Türkçe ile yazar."(MEB, 2006: 19) kazanımı "5. Türkçenin kurallarına uygun cümleler kurar."(MEB, 2006: 30) kazanımını doğal olarak içermektedir.

Bir dilin standart biçimi yazı dili olarak kullanılan ölçünlü dil olduğundan cümle teşkilleri dil kurallarına uygun olmak durumundadır. Bu açıdan bakıldığında standart Türkçe ile yazma, Türkçenin kurallarına uygun cümleler kurmak anlamına gelmektedir. İki kazanım, genellik özellik açısından bir arada değerlendirildiğinde "4. Standart Türkçe ile yazar."(MEB, 2006: 19) kazanımı genel ve kapsayıcı, "5. Türkçenin kurallarına uygun cümleler kurar."(MEB, 2006: 19) kazanımı bu kazanıma göre daha özel ve kapsanan durumundadır. Bu sebeple "4. Standart Türkçe ile yazar."(MEB, 2006: 19) kazanımına "Türkçenin kurallarına uygun cümleler kurar." açıklaması eklenebilir.

2. Yazma kurallarını uygulama amacı altında yer alan "7. Olayları ve bilgileri sıraya koyarak anlatır.", "8. Yazısında sebep-sonuç ilişkileri kurar." ve "9. Yazısında amaç-sonuç ilişkileri kurar." kazanımları planlı yazma amacı altında yer almalıdır.

Planlı yazma amacında "2. Yazacaklarının taslaklarını oluşturur." kazanımı bulunmaktadır. Olayların oluş sırası ya da bilgilerin önceliklerinin belirlenmesi yazma planı ile ilgilidir. Ayrıca, yazı taslağı içinde sebep-sonuç ve amaç-sonuç ilişkilerinin kullanılması anlatım gücünü arttıracaktır.

3. Yazma kurallarını uygulama amacında bulunan "11. Yazım ve noktalama kurallarına uyar." kazanımı, Yazım ve noktalama kurallarını uygulama amacı altında iki kazanım olarak yer almaktadır.

Yazma kurallarını uygulama amacı altında yazım ve noktalama kurallarına uymaya yönelik bir kazanımın yer alması isabetlidir. Ancak, mevcut durumda kazanım tekrarı söz konusu olmaktadır. Yazım ve noktalama kurallarını uygulama amacı altında yer alan "1. Yazım kurallarını kavrayarak uygular." ve "11. Yazım ve noktalama kurallarına uyar." kazanımları ve açıklamaları yazma kurallarını uygulama amacı altında verilmelidir.

4. Planlı yazma amacında bulunan "5. Konunun özelliğine uygun düşünceyi geliştirme yollarını kullanır." kazanımı hedeflenen beceri gerçekleştirmek bakımından eksiktir.

Bir yazıda kullanılacak düşünceyi geliştirme yollarının belirlenmesinde konunun etkisi olabileceği gibi, konunun hangi türde ele alındığı da belirleyici olabilmektedir. Bu açıdan kazanımın "Yazılarında konunun ve türün özelliğine uygun düşünceyi geliştirme yollarının kullanır." şeklinde düzeltilmesi gerekmektedir.

Aynı kazanımın açıklaması "2.5. Tanımlama, betimleme, örnekleme, karşılaştırma, tanık gösterme, benzetme ve sayısal verilerden yararlanılarak ana fikir desteklenir." şeklinde eksik olarak yapılmıştır. Açıklamalarda anlatım tarzları olan açıklama, tartışma, betimleme ve öyküleme üst kategori düşünceyi geliştirme yolları olarak yer almalı; her bir anlatım tarzında kullanılan alt kategori düşünceyi geliştirme yolları da sıralanmalıdır.

5. Planlı yazma amacında yer alan "11. Dipnot, kaynakça, özet, içindekiler vb. kısımları uygun şekilde düzenler." kazanımı işe vuruk değildir. 
Kazanım ilköğretim öğrencilerinin seviyelerinin üstünde bir yazma becerisini gerektirmektedir. Mevcut haliyle, akademik olarak üretilmiş bir kitabı tanımlamaktadır. Bu açıdan öğrencilerde beceri olarak gerçekleşmesi oldukça güçtür.

6. Kendi yazdıklarını değerlendirme amacı ve bu amaç altında yer alan kazanımlar sonuç değerlendirmesine dönüktür. Bu amaç ve kazanımlar yazma sürecinin değerlendirilmesi de kapsayacak şekilde yeniden düzenlenmelidir.

Öz değerlendirmenin sadece sonuca odaklı gerçekleştirilmesi yeterli görülmemelidir. Yazma sürecinin öğrenci tarafından değerlendirilmesi öğrencinin farkındalık düzeyini arttıracaktır.

7. Kendi yazdıklarını değerlendirme amacı altında yer alan kazanımlarda aşırı genelleme yapılmıştır.

"1. Yazdıklarını biçim ve içerik yönünden değerlendirir." kazanımda yer alan biçim ve içerik özellikleri ile "2. Yazdıklarını dil ve anlatım yönünden değerlendirir." kazanımda yer dil ve anlatım özellikleri yazma kurallarını uygulama ve planlı yazma amacı altında birden çok kazanımla verilmiştir. $\mathrm{Bu}$ özellikler dikkate alınarak, kendi yazdıklarını değerlendirme amacı altında kazanıma dönüştürülebilir.

\section{Sonuç ve Öneriler}

Halen yürürlükte olan Illköğretim Türkçe Dersi Öğretim Programı $(6,7,8$. Sınıflar) üzerine gerçekleştirilen bu çalışmada konuşma ve yazma öğrenme alanlarının kazanımları eleştirel bir bakış açısıyla değerlendirilmiştir. Çalışmada elde edilen temel bulgular ile bunlara ilişkin öneriler şunlardır:

1. Öğrenme alanlarının bütün özellikleri kazanımlara yansımamıştır. Bu durum kazanım eksikliğidir.

Her iki öğrenme alanının kazanımlarında da öğrenme alanlarının bütün özelliklerinin kazanımlaştırılmadığı görülmektedir. Konuşma öğrenme alanında, günlük yaşamdaki iletişim intiyaçlarının giderilmesi açısından önemli olan karşıııkı konuşmaya ilişkin kazanım bulunmamaktadır. Her iki öğrenme alanında söz varlığına ilişkin bir amaç yer almazken söz varlığı ili ilişkili bazı kazanımların diğer öğrenme alanları içinde yer aldığı görülmektedir.

2. Bazı kazanımlar yanlış ifade edilmiştir.

Kazanımların ifadelerinin açık, net ve tutarlı olması gerekir. Bu durum uygulamada oluşabilecek tereddütlerin engellenmesine yardımcı olacaktır.

3. Bazı kazanımlarda aşırı genelleme söz konusudur.

Kazanımlardaki aşırı genellemeler, kazanımlar için etkinlik hazırlamayı güçleştirmektedir. Kazanımların kolayca etkinliğe dönüştürülebilmesi ve eğitim sürecinde ölçülüp değerlendirilebilir olması önem taşımaktadır. Genel kazanımların birden çok kazanıma dönüştürülmesi ile sorun çözülebilir.

4. Öğrenme alanları içinde kazanım tekrarları bulunmaktadır.

Türkçe Dersi Öğretim Programı tam olarak sarmal program özelliği yansıtmamaktadır. Konuşma ve yazma kazanımları uygulamada her sınıf düzeyi için aynı biçimde geçerlidir. Bütün kazanımlarının bütün sınıf düzeylerinde geçerli olması uygulamada zamanın ekonomik kullanımını engellemektedir. Aynen tekrar edilen ya da birbirine çok yakın anlam taşıyan kazanımlar birleştirilmelidir.

Son olarak, anlatma becerileri açısından son derece kritik olan eş zaman ve art zamanlı düşünmeye ilişkin programda herhangi bir kazanımın yer almaması dikkat çekidir. İlköğretim öğrencilerinin zengin bir anlatım yapmalarında bu düşünme biçimleri belirleyici olmaktadır. Bir beceri olarak doğru düşünme, yakın ve uzak çağrışımları kullanarak anlatımı zenginleştirme açısından öğrencileri geliştirecek kazanımların programa eklenmesi gerekmektedir. 


\section{Kaynakça}

Baş, B. (2012). İlköğretim Türkçe programına sözlü ve yazılı kültür temelli bir eleştiri. Kastamonu Eğitim Dergisi. 20(1), 271-290.

Erden, M. (1998). Eğitimde program değerlendirme. Ankara: Anı Yayıncılık.

Karadağ, Ö. (2012). Anlama becerileri açısından Türkçe dersi öğretim programı (6, 7, 8. sınıflar)'na eleştirel bir bakış. CÜ Sosyal Bilimler Dergisi. 36 (1), 97-110.

Milli Eğitim Bakanlığı. (2006). İlköğretim Türkçe dersi öğretim programı ve kılavuzu (6, 7, 8. sınıflar) Ankara: Devlet Kitapları Müdürlüğü.

Milli Eğitim Bakanlığı. (2005). İlköğretim Türkçe dersi öğretim programı ve kılavuzu (1-5. sınıflar) Ankara: Devlet Kitapları Müdürlüğü.

Özçelik, D.A. (1992). Eğitim programları ve öğretim. Ankara: ÖSYM Yayınları.

Varış, F. (1976). Eğitimde program geliştirme. Ankara: Ankara Üniversitesi Eğitim Fakültesi yayınları No: 53.

Yalçın, A. (2002). Türkçe öğretim yöntemleri. Ankara: Akçağ Yayınları. 